\title{
Reflections on Ludification: Approaching a Conceptual Framework - And Discussing Inherent Challenges
}

\author{
Bo Kampmann Walther ${ }^{1}$, Lasse Juel Larsen ${ }^{1}$ \\ ${ }^{I}$ Department for the Study of Culture, University of Southern Denmark, Odense, Denmark \\ $\{$ walther, ljl\}@sdu.dk
}

\begin{abstract}
This article discusses the relatively new concept of ludification with the attempt of laying the theoretical groundwork for further studies. Although ludification ties in with both gamification and the concept and practice of transmedia it possesses unique characteristics and qualities of its own, primarily evolving around games and playful ways of structuring stories. The focus point is how traditional media such as tv-series and movies incorporate gamelike traits and structures into their narrative structure. This concerns both the narrative structures that users can and cannot interact with. Among other things, we consider a deep understanding of ludification vital for the more practically oriented approach to learning through (serious) games. Thus, this paper serves as a prolegomenon to the interpretation of works of ludification, as well as to the diverse field of deploying gamified material in didactical and pedagogical context. In addition to the conceptual groundwork for understanding ludification and how it manifests itself we propose an analytical method for unearthing the traits and structures of ludification: we have coined this method the ludo-interpretation. Furthermore, this article discusses the merits and shortcomings of ludification and the ludo-interpretation in the final section where we deploy a Popperian inspired three-levelled falsification and refutation technique.
\end{abstract}

Keywords: Ludification, Gamification, Play theory, Game design, Learning

\section{Introduction}

In an American perspective ludification has come to mean the use of game systems for business and government applications thereby placing the term confusingly close to another debated term: gamification. However, there is no clear-cut consensus about terminology as regards both terms in the literature. Even though the term ludification is widely used in cultural studies where it broadly signifies the introduction of elements of play and gamefullness into our lives and of culture as a whole [1], we still need a conception of ludification that makes it possible to differentiate between gamification and ludification.

We regard ludification as a concept that concerns how storytelling across media, tvseries and movies integrate computer game traits and structures in their narrative composition. We propose the term ludification, rather than transmedia; the question of ludification is not about how stories migrate between different media, but how computer games attributes and structures influence a host of different media. In short, we comprehend 'ludification' as a robust enough concept to not become merely a subset included in the terminology 
of either gamification or transmedia. Ludification is connected to both, gamification and transmedia, but still, it possesses unique characteristics and qualities of its own.

Thus, the goal of this article is to demonstrate and reflect upon how computer game traits and structures influence traditional narratives: especially cinematic storytelling. However, to pinpoint how computer game traits and structures can be explored and unearthed we use a specific method called the ludo-interpretation, i.e., reading traditional media through the lens of computer games, which we have outlined more operationally in [2] and [3]. Although this can of course only be hinted at here, such scrutiny ideally makes way for a better understanding and a more fitting classification of ludification, and in addition provides a theoretically informed working model for the serious use of ludified material in assorted contexts.

Next up, in section two, we will outline the conceptual framework of gamification, followed by the third section in which we investigate the design principles of using computer game elements and game mechanics [4] [5] in non-game settings [6]. The fourth section discusses how gamification rests on rewards as triggers for situational motivation. The fifth section dives into conceptualizations of play and playfulness discussed vis-à-vis computer games, gamification, and ludification. Section six examines the sociological claims about the 'rationalization' of play as specific and often destructive forms of social ordering leading up to a broad profile of ludo-interpretation, section seven. Section eight casts a critical view on the concept of ludification, what it offers to the understanding of computer games, gamification, and storytelling, and the challenges and inherent problems it raises. Finally, in the concluding section nine, we tentatively offer thoughts on the connection between ludification and learning.

\section{Gamification}

Gamification is, as already hinted, often interchangeably understood as ludification [7]. The conflation of the two terms is unfortunate, especially since there are several differences between the two.

The fate of gamification has been the subject of hot debates [8]. In those debates, gamification associates with terms like 'gameful' [9], 'gamified', and 'gamefulness'. But what do these terms mean? 'Gameful' and 'gamefulness' seem to point toward the experience of the player engaged in game-like activities. 'Gamified', on the other hand, seems to signal design, that is, how one may apply game-like elements to a wide range of topics and areas typically located outside the realm of computer games. This conceptualization that almost results in disarray has led to a tentative, porous, and broad definition of gamification as '[the] use of game design elements in non-game contexts' [6]. Despite its far-reaching scope gamification is associated with a specific design practice by which game elements are applied to a wide sample of topics and activities in different contexts. This practice has been labelled 'gameful design', 'gamified design', 'applied game', as well as 'applied game design' [10].

However, to clearly differentiate between gamification and ludification we propose the following definition of ludification as the use of game design elements in non-game contexts with a special emphasis on story structures and story objects in narratives. Later, we shall investigate the theoretical challenges in this rather formalistic definition.

Narrative is not the only difference between the two concepts. Another difference has to do with learning and motivation. Central to this is the notion of how users' interaction with game-like features in non-game contexts promote engagement and accelerate learning, usually through some kind of reward system [11] [12]. Overall, the rationale for gamification rests on a somewhat dubious claim: that video games are heavily dependent upon rewards, and that players desire and respond well to being rewarded. Furthermore, this implicit behavioristic rationale is merged with the observation that video games engage players. Ergo, the causal steps in the thinking of gamification seem to suggest that players get 
engaged in video games because they get rewarded. Here engagement is deeply tied to the notion of rewards thus disregarding all the other aspects of game design [13] [14]. Important in this context, however, is that this way of thinking opens a mesmerizing scenario of harvesting the sway computer games hold on players and apply it outside the realm of games, especially learning. The sheer thought of the endless possibilities is enough to cloud even the fiercest critic - computer games are, commercially and conceptually, a goldmine.

\section{The design practice of gamification}

Let us focus a bit more on the design approach of gamification with its declared ambition to use computer game elements to engage and motivate users to accelerate learning [8]. One difficulty that emerges is how to cope with the intricacies of game design. These intricacies fuel several different answers as the growing catalogue of research into computer games demonstrate. One aspect stands out as unclear, namely the distinction between the machinery of computer games, in general, and designing for gamification. The reason for this blurred distinction has to do with players' recognition of the interactive gamified system and its properties. Do players perceive the system as gamified content, or do they regard it as a computer game? Add hereto another important and equally unclear border, which loops around the question of learning: what kind of learning and knowledge the gamified system is designed to promote. There exists yet another vital issue, which concerns motivation. Specifically, whether the gamified system relies on intrinsic or extrinsic motivation to engage players [15] [16]. On top of these three unclear borders a deeper and transcendental question roams: what does it take to make a system engaging to interact with [17], whether the need for clear goals, manageable challenges, or transparent and quantifiable outcomes?

All this questioning, from the nature of gaming to the valorization of goals, leads to fundamental design reflections on how to understand formal computer game elements and combine them in relation to an intended learning outcome. As such, the conceptual scrutiny of games (what they are) and the functional applicability (what they are good for) weave into one another. For instance, posing the question, does it make sense to reward the user with a star when she is trying to learn a new language, implies a causal connection between practical upshot (language skills) and the conceptual premise that games are splendid tools with which to reward users when they achieve a goal.

All these borders are, as already stated, blurred. Nevertheless, they rise from the same rift in the rationale of gamification; the gap between utilizing a specific set of aspects of computer games on the one side and fully-fledged computer games on the other side. This rift has not been bridged and as a result we are left with these blurred borders. They come into light when one asks oneself the simple question how many computer game aspects and specifically which ones - are needed before a 'gamified' system tilts and becomes a fully-fledged video game. There is no clear answer to this question. Yet, until now the focus, in research at least, has been on computer game aspects such as clear goals, feedback in the form of quantified rewards and measurable progress normally in the shape of badges, levels, and leader boards [11]. However, these aspects constitute only a small part of all the numerous elements of designing and understanding computer games.

\section{Reward}

The rationale of gamification, as mentioned above, assumes that reward systems relate to motivation. However, the question of how to design a reward system that can drive the desired behavioral changes is another matter entirely. Despite this obvious challenge almost 
all research on gamification dodges the explanation of how to design a reward system beyond the meagre notion of handing out a badge or a star for a job well done.

This illustrates a curious lapse of attention. Especially since motivation and reward go together in the raison d'être of gamification. Therefore, it would seem obvious that research would center on principles for designing reward systems in relation to motivation in order to instill behavioral effects (on playful humans). However, this is far from the case. Let us be more specific and exemplify our critic by illustrating how a reward system triggers the activity levels of the user. Noteworthy in this regard is John Hopson's investigation of behavioral game design [18]. Hopson is inspired by neo-behaviorism and contemporary behavioral psychology. He argues that it is possible to a certain degree to 'filter' structural motivational parameters and gauge their effects. What we have, then, is a design structure of rewards.

This reward system, according to Hopson, can be designed through contingencies and schedules. A contingency is a rule, which governs when a reward is given out (hence the scheduling). Essentially, there exits two different kinds of contingencies, ratios and intervals, which can be both fixed and variable. Each produce different patterns in player activity, which is important considering motivation and learning.

Ratio schedules are dependent on the user's activity. They provide the user with a reward after a specific number of actions have been taken. When this is translated into a task, it would sound something like this: the game presents the player with a task of killing X orcs or to solve Y math assignments [19]. In both cases, the player will be rewarded following a specific number of actions. This is called a fixed ratio schedule since it requires a finite number of actions before the reward is provided. Note that the specific number of actions required have been announced beforehand and that the number of actions never change. If the player begins the game anew the same task will require the exact same number of actions before the reward is given. Nothing changes. Most noteworthy, however, in the fixed ratio player activity begins very slowly with a short sudden burst of energy toward the end. The opposite happens with the variable ratio. Here, the player activity levels are constant and fairly high. In other words, the player performs the same action repeatedly in anticipation of a reward even though the reward fails to materialize itself.

This design structure is contrasted by the interval schedules, which also can be both fixed and variable. When they are fixed, they depend on the internal clock of the game system, i.e., interval schedules provide rewards after a certain amount of time has passed. There is no need for player activity. The reward will be provided regardless of player actions or not. The opposite holds for the variable interval schedule, which constitutes a reward after a variable time period. Sometimes, the reward is provided after 30 seconds, while at other times the reward is revealed after five minutes. Here, the players' activity levels follow the fixed (slow in the beginning accelerating toward a burst in the end) and variable (steady and fairly high) pattern of behavior. The correlation between the structural design of rewards and the users' response and behavior seems to escape the studies of motivation within the field of gamification, i.e., how the structural design of rewards drives behavioral changes both in the short, intermediate, and long term.

\section{$5 \quad$ Play and playfulness in light of ludification}

Studies of ludification have mostly been related to media production and how playfulness and a certain gaming sensibility create new cultural practices [20]. They involve the consumption of new media and how it reconfigures, reshapes, and transforms both the media itself and the wider ecology around it [21]. Such approaches express a change 'from a predominantly narrative to a predominantly ludic ontology' [20]. This change is particularly true of the role of play in modern culture [22]. However, such formulations are broad and abstract. They suffer from lack of clear definitions and discussions of play and game, which are important when the subject matter is either gamification, ludification or both. We will 
address the intricacies of conceptualizing play and game in relation to gamification and ludification in this section.

However, from a conceptual standpoint it is important to elaborate and situate the accepted term convergence in relation to play, game, and ludification in order to avoid misunderstandings.

Firstly, media convergence, as defined and discussed by Henry Jenkins [23], represents the flow of content across media platforms (together with convergence of technology; previously discrete units of hardware were separated; now they converge into a single unit) added with an emergent and increasingly powerful participatory culture where users playfully distribute, produce, and engage with content to make meaningful connections [24] [25]. The role of identity constitution through media no longer consists of passive reflections or (direct) effects of media consumption. Instead, the dynamic of ludic identity creation is reciprocal and tied to users' activities with new media. Such activities shape user practices which in turn are (re)configured by new media formations.

Ludification can, in this light, be viewed as a cultural and social practice situated at the intersection between play, playfulness, game, and gamefulness [26]. Thus, play and playful attitudes together with computer games and gamefulness find themselves 'at the heart of a dispersed ecology of practice, diffused from local identity creation to global cultural production and usage' [27].

Secondly, the entanglement of convergence and ludification springs from the disruption of the sharp border between production on the one side and reception on the other, which seems to be influenced by Johan Huizinga's definition of play in his highly influential work Homo Ludens [28]. According to Huizinga play acts as an inspirational force, which propels the development of culture. Play is different from work, Huizinga writes, in that it does not have a utilitarian purpose. Play seems to 'float' awaiting materialization either in the shape of an arena or board of sorts or by the contextualization of playful activities. Huizinga's distinction between work and play is echoed by Caillois [29] when he describes play as 'pure waste'. Huizinga and Caillois' shared epistemology of play, it could be argued, originates from Protestant ideology as it is portrayed by Max Weber [30]. The overall perspective is that play is unproductive as opposed to work, which is a productive and meaningful activity. Thus, play exists outside ordinary life, adheres to its own rules and carries no material interest. Play is an unserious activity even though it has the capacity to fully absorb its participants and pose as a vital driver for cultural production.

Contrary to this view, Stevens [31] regards Huizinga and Caillois' split between play and work as 'a false dichotomy'. He criticizes Huizinga and Caillois for mixing and confusing the formal characteristics of play with the experience of being in play. This polarity smudges the boundaries, since 'we are taking the behavior for the experiencing of that behavior' [31]. Stevens' solution is to separate form from experience or poetics from aesthetics, which further means separating the formal markers of play from the experience of being-in-play. This approach in drawing clear boundaries reflects several research traditions within the humanities, which can be illustrated with an example from Russian formalism.

The Russian formalists were not interested in play (or, more general, representational artforms) per se. Instead, they wanted to formally divorce literature from non-literature. Shklovsky, in his now classic essay "Art as Technique" [32], draws a defining line between what can be considered art (literature) and what cannot (non-literature). This line, Shklovsky says, belongs to the concept of 'defamiliarization'; a device or perceptional trigger that forces the reader to see the already acquainted in a new light. Guided by Shklovsky's device of defamiliarization, Tomashevsky, in a later essay called "Thematics", from 1925, meticulously outlines the specific units and the order of narrative elements that are present in literature [33]. Two distinct layers exist within the narrative design of literature: story (fabula) emerging as the chronological order of events; and that which appears as the presented story (sjuzet). Thus, story is the unedited sequence of events as opposed to the edited plot, which is the defamiliarized composition of the chronological order of the story.

What is relevant here is that Stevens seems to echo the overall mode of thinking of the Russian formalists. This does not mean, however, that Stevens is a straight-faced formalist; 
on the contrary, Stevens illuminates the flipside of the formalist coin, the experience. Steven's focus on the experience of play echoes Hans-Georg Gadamer's phenomenological analysis of play [34]. He too separates the experience of being in play from the formal structure of play [35].

Stevens' turn away from the formal analysis in return of an investigation of the inner workings of the experience of being in play opens up a novel approach to play. This approach allows for play to be seen as a particular and pleasurable attitude to an on-going, prosaic activity, including playful engagement with new media.

Let us now dive a bit deeper into the presented distinctions between the experience of play and the form of play, since they tie into the complexities of separating ludification from gamification; where they stand out from each other and where they overlap.

Play, T.M. Malaby writes, is 'a mode of human experience [...] a way of engaging the world whatever one is doing' [36]. This view of play implies that we can think of 1) play as a mode of experiencing; 2) play as a particular way of engaging with the world; and 3) play as a possibility, which can happen in all kinds of places and in any number of activities.

In a more recent study Malaby expands his position. Now play includes a disposition 'characterized by a readiness to improvise in the face of an ever-changing world that admits of no transcendently ordered account' [37].

Malaby's approach to play 1) prioritizes play over any given activity or practice; 2) and it insists that play holds a specific and situational stance, which always happens in a context. This point resonates with Sicart's take on play that it is an appropriative power that can 'take over' or colonize any unfolding activity [38]. 3) Finally, play seems to be alwaysalready tied to a specific situation, especially the role of play, which lends itself to navigating the indeterminateness of an ever-changing world.

We have now, with the help of Malaby, Stevens, and Sicart abandoned the traditional and 'false' dichotomy of work versus play. As Malaby puts it: "When the work/play distinction is left behind, we see instead in ludic practice a more useful contrast between a cultural form (a game-like activity, regardless of the level of playful engagement) and a mode of cultural experience (a playful disposition towards activities no matter how gamelike) [37].

However, when play is estranged from actual game activities, it is possible to treat play as an autonomous, conditional unit fundamental to the human condition. Play becomes, almost in a Heideggerian fashion, a disposition, or a mode of experiencing the world -i.e., play being the a priori framework for aposteriori and actualized gameplay [39].

\section{Rationalization of play}

But there is a darker side hidden in the entanglement of the dichotomy between 'play' and 'game', which spills over into the distinction between ludification and gamification. Grimes and Feenberg [40] write about play being mixed up with a form of social rationalization, which takes place at the junction of play experience and computer game systems. According to them 'play' reproduces 'the larger processes of rationalization at work within modern capitalist societies. Silverman and Simon [41] use the term 'power play', which they see as an act of 'machination', a submission of the player shaped by the computer game system. In pragmatic terms one can think of (the experience of) play transforming itself from being fun and engaging to a tiresome, boring, and work-like activity. Players no longer enjoy the game. Instead, they mechanically respond to the demands of the computer game system as their playful attitudes sublimate into rationalization. Rather than players playing the game, it is the game that plays and drives the players toward future rewards.

The silver lining in this dystopian perspective is Grimes and Feenberg's observation that players increasingly become part of the production of game content, which means that we should couple the view on the dark side of play with the 'social, cultural, and political 
conditions within which a computer game is appropriated and contested by its players' [40]. The premise of this claim is, like Stevens, Sicart and Malaby, the transgression of the work and play dichotomy.

Thus, rationalization may be a process that simulates 'work'; but it must be measured against the appropriating act of cultural counter production that play offers. Not only does play entail the dialectic of tyrannizing players from within the computer game system as well as to harvest a potentially liberating annexation. Play also creates 'a form of social order' [40]: "[It] is not that social order recapitulates certain features of games, but rather that games have themselves become forms of social order". This quotation from Grimes and Feenberg implies a dual set of premises: First, the distinction between the poetics of the system and the aesthetics of the play experience; and second, a peculiar flip-side version of Huizinga's claim: Namely, the idea that play not only propels forward the fruition of culture, but also that play is laden with interest, rather than being mere fun and dis-interested. Since play, then, really can exist as a kind of realization of its own promise, because it can foster a disruption of the hegemonic one-way-street of computer game systems; the vital (and perhaps sad) point here is that rationalization may come back to haunt players in the shape of not just the social ordering of games, as Grimes and Feenberg writes, but also as the instrumentalization of play.

Nevertheless, play itself holds transformational capabilities; not statically, but dynamically, while percolating from play mode to game mode. Play passes from an undifferentiated state of playfulness to a rationalized configuration adjusted to fit the computer game system. This transformative process takes place through a series of differentiations [42] [43], which end up subjugating play in such a way that play bends to the will of the computer game system. This is not the instrumentalization of play, but, rather, the inherent and almost evolutionistic dynamic of the activity: play lends itself to and is drawn towards the game format. In other words, play exists in a continuum between play mode and game mode, which alludes to Caillois' conceptualization of play where play takes place in a band between paidia and ludus. Paidia (mostly translated as 'free play') embraces the precipitateness and spontaneity of play, play mode, and is contrasted by the much more disciplined ludus. Caillois himself explains the two poles respectively as 'diversion, turbulence, free improvisation, and carefree gaiety [and] ever greater amount of effort, patience, skill, or ingenuity' [29].

To play a game is to be swept away by and drawn into a series of transformations - a rationalization process which ends up quelling play, according to Grimes and Feenberg. Callios sees it differently. What could be called game mode is merely the maturation of 'diversion' and 'turbulence' as well as the effect of paidia gradually 'becoming' ludus with all its 'effort, patience and skill'.

One could say, partly conclusive, that there lies an inherent ideological stance in play's subjugation to game, pace Grimes and Feenberg. Callios, on the other hand, is much more akin to the idea of the evolutionary and dynamic processualism of play and games. In addition, play mode and game mode resemble Malaby's 'cultural form' and 'mode of cultural experience'. Both evolve in an overlapping continuum while keeping both aspects open for on-going configurations.

These dynamics inject play into the process of ludification. Play activities transform from undifferentiated to differentiated states though optimization, discipline, and self-referential awareness. It is this process that ascribe to the social order while simultaneously creating opportunities for user resistance and creativity. One could say that the procedural wave of play turning into game means both to 'fit in' to the power structure of games but also to make play 'stand out'. Ultimately, there is an element of instrumentalization in the dominance of the game mode and the way it takes control over, and disciplines play. And yet there is equally, and simultaneously, an imaginative resonance in the very same playfulness that sparks a counter strategy, which reacts to and seeks to transform the dominance of the game.

Ludification, thus, is a process which injects playfulness and gamefulness (game structures) into tv-series and movies. In contrast to this process, gamification inserts game-like 
progress patterns and reward structures outside the realm of games, especially within the domain of learning.

Together, ludification and gamification reside in a circular and recursive formation accelerating and expanding the ludic presence of game-like traits outside the realm of (proper) games.

\section{The ludo-interpretation}

One could say that media production, in its most generalized and 'empty' form, is subject to the same dialectical process players find themselves in when playing games. Media production, then, is a metaphor for players preoccupied with not only the kind of mastery and discipline that games require but also with the 'turbulence' and counter strategies of playfulness, Callios' paidia. When media production seizes computer game functions, computer game architectures, and computer game experiences and apply them to the narrative composition of television series and modern cinema the result is a new ludic sensibility, as well as new sites of rationalization (gamefulness) and imagination (playfulness). This sensibility is subject to the influence of computer games and therefore to computer game functions, computer game architectures, and computer game experiences.

Thus, finally, out of the hazy breath of play's appropriation and game's discipline ludointerpretation surfaces as the locus of deep understanding.

When it comes to ludification a pragmatic and an ideological point must be made. Pragmatically, the interpretation of ludified works (say, television series or blockbuster movies) is wedged between the media on the one hand and the spectator on the other hand. This division is firmly seated within the 'classic' tradition of television and movie analysis that distinguishes between media including its hosts of devices and story propelling utensils, and the spectator as the center for reception and interpretation [44].

In ideological terms, however, the interpretation of ludification is obliged to perform a specific task. This task is to decipher the pressures between the explicitly playful appropriation of computer game functions, architectures, and experiences by media production, and to look closer into the way this production is implicitly influenced, disciplined, and dominated by computer game functions, computer game architectures, and computer game experiences (see examples in [27], [2] and [3]).

It goes without saying, that all this play and games stuff is most of the time implicit and hidden. Ludo-interpretation is no different from every other literary, cinematic, or ludological reading technique: It triumphantly wishes to illuminate - explicate - that which is concealed below the surface: in this case how game structures find their way into narrative structures and vice versa.

And yet there are many times when the bells and whistles of contemporary ludification are overtly explicit. The action hero deploys a finite number of actions, which yield experience points (XP) and upgrades his/her power in the game/story space. Sony and Disney wish to implement level design into their feature films. The fascination with time travel and temporal complexity in contemporary television series - Lost, True Detective, Dark - may be viewed as a hermeneutic cornucopia; but it is also, quite simply, heir to the pragmatic navigation of many a video game in which teleportation and other 'beam me up' installations are common traits. The explicit and implicit renderings of ludic storytelling manifest as devices which serve to drive the story forward. Sometimes, these devices are easily recognizable. At other times they are obscured, cloaked, and masqueraded. Therefore, to unmask the explicit and the implicit influence from computer games within the design of contemporary television series and modern cinema, ludo-interpretation requires a particular attunement to the beforementioned dialectic of play and games, appropriation, and discipline, together with a sure footing in game design: computer game architectures, game mechanics, and play experiences. 


\section{Deep problems in conceptualizing ludification}

Most often, trying to establish a 'new' conceptual framework and additionally proving its worth in a more operationally analytical fashion is tricky. Consider, for instance, the bumpy road of 'ludology' as it faced the infamous debate of 'ludology versus narratology' [45]. Should the study of (computer) games be totally freed from any notion of literary techniques and hermeneutics; or was ludology rather to be seen as a special and almost revolutionary case of interactive storytelling [46]? In working as we do with how games, new media, and fictionality crisscross to produce unique modes of expression, media production and reception - a work in progress which is not at all linear - we are inspired and propelled to tackle both explicatory challenges and the conceptually inherent problems of ludification. Here, in this paper, we offer a snapshot of (some of) these problems which we find to be symptomatic. They play out on three scientific levels: The science theoretical, the methodological, and the analytical. We call them deep problems; henceforth the abbreviations DP-1, DP-2, and DP-3.

DP-1: On the science theoretical level one may ask, rightfully, why our definition of 'ludification' appears so rigid invoking a formalism very close to that of structuralism (or the early days of Ludology)?

The answer to this is rather complex and, in fact, raises the same potentially debunking strategies as those of structuralism, which we touched upon earlier: the need for universality. This would be the short (and very Popperian) answer [47].

The rationale behind this answer is that the more universal the theoretical definition becomes it also inevitably looms in on a kind of auto-prophecy by which the operationalizations that follow from it seem to state the obvious: Yes, ludified story-architectures and objects can and must be interpreted according to the theory as ludified architectures and story objects - since the theory and the definition of it is about such ludified architectures and story-objects.

However, the deeper reason for our rather rigid and formalistic definition is to build a conceptual construction that can resist what Graham Harman calls 'undermining' and 'overmining' [48]. One can undermine objects by claiming that they are a manifestation of a deeper, underlying substance i.e., a structure. Similarly, one can overmine objects by either an idealism which holds that there is nothing beneath what appears in the mind or, as in social constructionism, by positing no independent reality outside of language, discourse or power.

Since we wish to operate analytically (in other studies) on behalf of a theory and a conforming definition that has the explanatory power and flexibility to move beyond undermining and overmining, the definition must be construed in such a fashion that it neither posits an implicit claim of something 'hiding' beneath it (undermining) nor, contrary to this, resolve into a non-universal theory, which only upholds its legitimacy because of a higher order phenomenon (overmining).

DP-2: On the methodological level a valid question would be: Why does the theory of ludification and the corresponding method of ludo-interpretation so forcefully disrupt any notion of 'hermeneutics' in favor of a clinical - and dangerously descriptive - observation of game elements?

There is a brute answer and a more subtle answer to this objection. The brute answer is important when analyzing ludified story elements in linear narratives in order to pinpoint those mechanisms that enable movement, which is to say the action that this movement involves, rather than projecting sumptuous meanings of socio-cultural concerns onto those actions (this would be, by the way, an example of overmining; see DP-1). 
Effectively, what this means is that the ludo-interpretation is a reading strategy, which must (ideally) shy away from the notion (and practice) of subtextuality. For instance, the 'SUV' Jack Bauer uses in the television series 24 is, seen from a ludo-interpretative perspective, exactly not to be read as a subtext revealing the complex interaction of control and territorial dominance, on the one hand, and alienation and territorial threat, on the other [2]. For ludo-interpretation to avoid the threatening grip of overmining that goes on here, it must become a strategy of hermeneutical negation. This means ruling out rather than accepting any socio-cultural, political, or narratological signs in order to arrive at the ludic nucleus of the story-game.

Yet, there is also a more subtle response to the DP-2 question, since there's no point (or no future) in having a theory of ludification without any kind of hermeneutics. More specifically, unravelling computer game architectures and story objects in linear media texts and juxtaposing them with the techniques of ludo-interpretation is obviously inspired by the study of non-linear texts. This methodological move is in itself not a finding, but a strategy, which involves and insists upon a certain mode of 'hermeneutics of suspicion' the kind of hermeneutics that one also find in ludo-interpretation. For an illustration, think of Freudianism or critical theory, among others. These interpretative approaches engage in particularities of the text. They would most likely read the 'SUV' in 24, or the 'donkey wheel' in the television series Lost, as symptomatic traits of a wider, ludic, and playful culture of media production and reception, as we described in previous sections.

Fundamentally, then, it would be fair to say that hermeneutics of ludo-interpretation works on two simultaneous levels: First, on the operational level it seeks to bypass traditional hermeneutics to unveil the 'proper' game (and gaming) elements of the text. Second, on the science strategic level it maneuvers to generalize (arguably) symptomatic features - which the method steers its classic notion of suspiciousness towards.

DP-3: The third deep problem, which is analytical by nature, raises the concern that in order to analyze ludified architectures and story objects that are essentially linear one must (wrongfully) adopt the conceptual language of digital games (and therefore of the computer as machine). In other words: Can linear story objects be at all 'ludic' since they are not, materialistically speaking, interactive?

Again, this is a multi-faceted objection, but to provide a tentative answer it is necessary to distinguish between three parameters with which to test not only the 'range' of interactivity but also the 'nature' of it. Thus, we distinguish between interactivity - in its most flexible form - as A) either systemically internal or external; B) having a non-trivial effect or no effect; and, finally, C) interactivity as belonging to an ontological or epistemological explanatory domain.

Now, it follows from our definition (see DP-1 and the beginning of this paper) that linear story architectures and objects that can be said to somehow 'simulate' a digital environment in which there is a materialistic basis for interaction do not change output (or 'state', as computer scientists would say) due to an interaction. Why? Because this interaction (unless one is watching/playing Bandersnatch) is performed by an external observer. This means that the 'system' in question contains no mechanism that would trigger an interaction that again would cause a new output or change in the aforementioned 'state' of the "game" (tvseries or movie). The opposite would hold true of the computer as a machine and when speaking about proper computer (digital) games, also known as automated state machines. Then the mechanism that 'invites' interactivity is an in-build feature of the internal system, and the corresponding input (by the player) is likewise an immanent part of the interactivity configuration. When dealing with ludification and the practice of ludo-interpretation it is therefore vital to remember that any interaction (whether in the shape of observation, contemplation, or imagination) does not affect the materialistic configuration of the machine - the tv series or movie. A materialistic interaction (such as the computer) and a non-materialistic interaction (such as an external observer pondering a piece of art) may both be 
semiotic in nature as they evolve around a process of semiosis and interpretation. However, only the former is cybernetically interactive.

This brings us to the last differentiation, that between ontology and epistemology. Since ludified architectures and story objects only behave like non-trivial, digital game elements which, in turn, have state changes built into their internal configuration, and since, henceforth, such architectures and objects cannot be those game elements, then ludification must necessarily (and only) operate on an epistemological level. Thus, every objection against ludification and ludo-interpretation that addresses the ontology must be met with a certain amount of skepticism.

In addition, the test of under- and overmining, pace Harman, is crucial in this respect: 1) One might insist that the phenomenon of interactivity becomes a 'missing' element in the explanatory reach given by the definition of ludification. This means that not only does the definition loses its universal power, since something underneath it (i.e., interactivity) escapes its attention; but furthermore, that ludo-interpretative readings of linear story-objects behaving like games are inherently 'false' (since they do not tell the whole story). 2) The same logic, but in the opposite direction, would apply to overmining: The phenomena of ludified architectures and story-objects ought, as we explained above, be analyzed as if they belonged to the ontological domain of digital games precisely because of their epistemological nature. If not, that is, if one does not insist upon this 'epistemologization' of what is otherwise plain 'ontology' in non-linear texts, the ludified architectures and storyobjects and what could be conjectured about them would run the risk of being overmined, or explained away, as having (only) prominent, hermeneutical meaning (and then we are back to DP-2).

\section{Conclusion}

As explained in this paper, gamification refers to the introduction of game elements and game mechanics in non-game objects, installations, and situations; in fact, gamification can be regarded as a subset of applied behavioral psychology because of the profound emphasis, as we saw above, on motivation, feedback, progress, and reward. Ludification relies on the same kind of infusion of game elements - but in another domain. Ludification concerns the enhancement specifically of game elements in stories - works of linear fiction.

Thus, one could say that a gamified architecture and objects are non-game architectures and objects endowed with components and traits from the gaming regime; while ludified architectures and story-objects are non-game story-architectures and story-objects endowed with similar game components and traits whose focus, however, is not on motivation, feedback, and reward but, rather, of ways of 'designing' and 'telling' stories in new and exciting, i.e., 'ludified' fashions.

The terminology that we propose here, which we outlined above, and with all the science theoretical, methodological and analytical challenges and inherent problems that we discussed in the previous section, constitutes a shift from ludification being merely a subset of gamification intended for specific non-game purposes to contemporary media productions and consumption practices where the co-existence of elements of play, game architectures, and game mechanics together with modes of storytelling - preferably across media - become more and more dominant.

Ludology, the academic study of computer games, evidently pawed the way for the understanding of games on a formal level (their ontology) as well as for insights into the experiences, community making, and playfulness associated with games, i.e., the epistemology of games. Tentatively, one could envision the same kind of progression undertaken by the study of ludification - ludified architectures and story-objects - as that of the science of ludology: From the formalistic enquiry into the nature or ontology of games (or ludified architectures and story-objects behaving like games); to studies of playful practices and 
reception communities arising from these architectures and objects and the way they are ludified; to, finally, modes of 'extracting' situational knowledge and learning from these architectures and story objects. In other words, a journey from the underlying, theoretical strata of understanding and categorizing architectures and objects to new and fruitful ways of using these ludified architectures and story-objects - and the deep understanding of them - in instrumentalized contexts.

Will ludification be the next wave of serious, mediated learning? Will ludo-interpretation be the next thing in new media readings? This paper has tried to sketch the base theory of such ludified architectures and story-objects, refutations, and conjectures. And, of course, only time will tell.

\section{References}

[1] A. Dippel, S. Fizek, "Ludification of Culture, The Significance of play and games in everyday practices of the digital era", in Digitalization: Theories and Concepts for Empirical Cultural Research, ed. G. Koch, London: Routledge, London, 2017. https://doi.org/10.4324/9781315627731-15

[2] B.K. Walther, L.J. Larsen, "The Art of Speed: The Ludification of Cinematic Television - The Case of 24", in Proceedings of the 5th International GamiFIN Conference, Levi, Finland, April, CEUR Workshop Proceedings, 2021.

[3] B.K. Walther, L.J. Larsen, "The Ludification of the German Netflix television series Dark: Complexities of Quantum Chance and the Game of Time", in Proceedings of ICACGET 2021: 15. International Conference on Advances in Computer Game and Entertainment Technology, Dec. 2021, Barcelona, Spain (in press)

[4] M. Sicart, "Defining game mechanics" Game Studies, 8. http://gamestudies.org/0802/articles/sicart, 2008.

[5] K. Burgun, Clockwork game design, 1st. Burlington, MA: Focal Press, 2015. https://doi.org/10.4324/9781315756516

[6] S. Deterding, M. Sicart, L. Nacke, K. O’Hara, D. Dixon, "Gamification: using game design elements in non-gaming contexts", in CHI 2011, Vancouver, BC, Canada, 2011.

[7] G. Kirkpatrick, "Ludefaction: fracking of the radical imaginary", Games Cult. 10(6), 2015, https://doi.org/10.1177/1555412014568665.

[8] I. Bogost, "Why gamification is bullshit", in The Gameful World, eds. P.S. Walz, S. Deterding, Cambridge, Mass.: MIT Press, Cambridge, 2014, https://doi.org/10.7551/mitpress/9788.003.0005.

[9] J. McGonigal, "I'm not playful, I'm gameful”, in The Gameful World, Cambridge, eds. P.S. Walz, S. Deterding, Mass.: MIT Press, 2014, https://doi.org/10.7551/mitpress/9788.003.0045.

[10] R. Schmidt, K. Emmerich, B. Schmidt, "Applied games - in search of a new definition", in ICEC 2015. LNCS, eds. K. Chorianopoulos, M. Divitini, J.B. Hauge, L. Jaccheri, R. Malaka, vol. 9353, Cham: Springer, 2011.

[11] P.S. Walz, S. Deterding eds., The Gameful World, Cambridge, Mass.: MIT Press, 2014. https://doi.org/10.7551/mitpress/9788.001.0001

[12] K. Huotari, J. Hamari, "Gamification" from the perspective of service marketing", in $\mathrm{CHI} 2011$, Vancouver, BC, Canada, 2011.

[13] T. Fullerton, Game design workshop: A playcentric approach to creating innovative games. 3rd ed. Amsterdam, Boston: Morgan Kaufmann, 2014. https://doi.org/10.1201/b16671

[14] J. Schell, The art of game design-A book of lenses. Boca Raton, FL: CRC Press, 2008.

[15] R.M. Ryan, E.L. Deci, "Intrinsic and extrinsic motivations: classic definitions and new directions", Contemp. Educ. Psychol, vol. 25, 2000, https://doi.org/10.1006/ceps.1999.1020.

[16] M. Csikszentmihalyi, Beyond Boredom and Anxiety - Experiencing Flow in work and Play, San Francisco: Jossey-Bass Publishers, 2000.

[17] R. Hunicke, M. Leblanc, R. Zubek, "MDA: a formal approach to game design and game research", http://www.cs.northwestern.edu/ hunicke/pubs/MDA.pdf, 2004.

[18] J. Hopson, "Behavioral Game Design", Gamasutra, http://www.gamasu-tra.com/view/feature/131494/behavioral game design.php, 2001.

[19] L.J. Larsen, "Objects of desire: A reading of the reward system in World of Warcraft", Eludamos Journal of Computer Game Culture, Vol. 6, No. 1, 2012.

[20] J. Raessens, "Playful Identities or the Ludification of Culture", Games Cult. 1(1), 2006, https://doi.org/10.1177/1555412005281779. 
[21] V. Frissen, S. Lammes, M. De Lange, J. De Mul, J. Raessens, eds., Playful Identities: The Ludification of Digital Media Cultures, Amsterdam: Amsterdam University Press, 2015. https://doi.org/10.1515/9789048523030

[22] J. Raessens, "The ludification of culture", in Rethinking Gamification, eds. Fuchs, M., Fizek, S., Ruffino, P., Schrape, N., Lüneburg: Meson Press, 2014.

[23] H. Jenkins, Convergence Culture - Where Old and New Media Collide, New York: New York University Press, 2006.

[24] H. Jenkins, S. Ford, J. Green, Spreadable Media, New York: New York University Press, 2013.

[25] A. Kerr, J. Kücklich, P. Brereton, "New media - new pleasures?", Int. J. Cult. Stud. 9(1), 2006, https://doi.org/10.1177/1367877906061165.

[26] S. Lindtner, P. Dourish, "The promise of play: a new approach to productive play", Games Cult., 2011, https://doi.org/10.1177/1555412011402678.

[27] L.J. Larsen, "Play and Gameful Movies: The Ludification of Modern Cinema", Games and Culture, Vol. 14: 5, 2019, https://doi.org/10.1177/1555412017700601.

[28] J. Huizinga, Homo Ludens: A Study of the Play-Element in Culture, Martino Publishing, 2014. https://doi.org/10.4324/9781315824161

[29] R. Caillois, Man, Play and Games, Urbana: University of Illinois Press, 2001.

[30] M. Weber, The Protestant Ethics and the Spirit of Capitalism, New York: Scribners, 1958.

[31] P. Stevens, "Play and work: a false dichotomy", Assoc. Anthropol. Study Play 5(2), 1978.

[32] K.M. Newton, [V. Shklovsky] 'Art as Technique', in Twentieth-Century Literary Theory, eds. M. Fuchs, S. Fizek, P. Ruffino, N. Schrape, London: Palgrave, 1997, https://doi.org/10.1007/978-1-349-25934-2 1.

[33] B. Tomashevsky, "Thematics", in Russian Formalist Criticism: Four Essays, eds. L.T. Lemon, R.J. Rees, Lincoln: University of Nebraska Press, 1965.

[34] H.G. Gadamer, Truth and Method, London: Bloomsbury Academic, 2013.

[35] L.J. Larsen, "Play and space - towards a formal definition of play", Int. J. Play, Taylor \& Francis, 2015, https://doi.org/10.1080/21594937.2015.1060567.

[36] T.M. Malaby, "Beyond play: a new approach to games", Games Cult. 2(2), 2007, https://doi.org/10.1177/1555412007299434.

[37] T.M. Malaby, "Anthropology and play: the contours of playful experience", New Literary History 40(1), 2009, http://dx.doi.org/10.2139/ssrn.1315542.

[38] M. Sicart, Play Matters, Cambridge, Mass.: The MIT Press, 2014. https://doi.org/10.7551/mitpress/10042.001.0001

[39] L.J. Larsen, B.K. Walther, "The Ontology of Gameplay: Toward a New Theory", Games and Culture: A Journal of Interactive Media 15(6), https://doi.org/10.1177/15554120198 25929, 2020.

[40] S.M. Grimes, A. Feenberg, "Rationalizing play: a critical theory of digital gaming", The Information Society, Vol. 25, 2009, https://doi.org/10.1080/01972240802701643.

[41] M. Silverman, B. Simon, "Discipline and dragon kill points in the online power games", Games Cult. 4(4), 2009, https://doi.org/10.1177/1555412009343572.

[42] B.K. Walther, "Playing and gaming: reflections and classifications", Game Stud. Int. J. Comput. Game Res. 3(1), 2003.

[43] B.K. Walther, "Reflections on the philosophy of pervasive gaming with special emphasis on rules, gameplay, and virtuality", Fibreculture J. 19, 2011.

[44] M. Smith, Engaging Characters - Fiction, Emotion, and the Cinema, Oxford: Oxford University Press, 2004.

[45] M.-L. Ryan, Avatars of Story. Minneapolis/London: University of Minnesota Press, 2006.

[46] G. Frasca, "Ludologists love stories, too: Notes from a debate that never took place", DiGRA 2003: Proceedings of the 2003 DiGRA International Conference: Level Up, Vol. 2, 2003.

[47] K. Popper, Conjectures and Refutations, London: Routledge, 2002.

[48] G. Harman, The Quadruple Object, London: Zero Books, 2011. 